\title{
David Milch filmography
}

This covers merely the shows on which Milch had a significant creative influence and writing input, and does not include his work as executive producer on other shows, or his uncredited contributions to film scripts. As detailed in this book, Milch had considerable creative authority over the following series, which included in many cases the final revision of scripts. I have therefore listed the major shows that he was responsible for overall (and dates indicating the period of his influence), rather than individual episodes that he is credited with.

Hill Street Blues (1982-87)

Beverly Hills Buntz (1987-88)

Capital News (I990)

NYPD Blue (1993-2000)

Brooklyn South (I997-98)

Big Apple (200I)

Deadwood (2004-06)

John From Cincinnati (2007)

Luck (20I2)

Deadwood (movie, 20I9) 